\title{
Study on strength property of Cement Kiln Dust treated expansive soil
}

\author{
S.L CUI, X.P WANG, M.J TIAN and Y.F Du \\ State Key Laboratory of Continental Dynamics, Geological Department of Northwest University, \\ Xi'an, Shaanxi 710069, China
}

KEYWORD: Cement kiln dust (CKD); expansive soil; shear strength; curing ages

ABSTRACT: In this paper, expansive soil is mixed with CKD in different proportions, and fast shear tests were conducted on the specimens with an certain initial water content and dry density; Furthermore, fast shear tests were also conducted for specimens with $10 \%$ CKD content ratio, when specimens were maintained for different curing ages separately, to investigate the effect of both CKD content ratio and curing age on strength property. Results showed that with the increase of CKD content ratios, shear strength was first increased, then decreased, the critical CKD content ratio was about $10 \%$. And the cohesive force changes obviously, while the internal friction does not have a remarkable change. With the growth of the curing age, the shear strength increased exponentially, tending towards stability after about 28 days.

\section{INTRODUCTION}

Expansive soils are a kind of soils that have significant swelling and shrinkage properties under changing water content, and have been detected in many parts of the world, such as Canada, China, South Africa, Jordan, Australia, the United States and so on. The clay composition is mainly composed of hydrophilic mineral of montmorillonite and illite. Because of the swelling pressure or contraction crack produced by absorbing or losing water, the harm expansive soil in engineering construction is repeatability, long-term and potential. How to reduce the swell-shrink characteristics of expansive soil has long been a common global research topic (Woeley, 1959; Seed et al. 1962). After Thompson (1966) proposed and studied the properties of lime treated expansive soil, the study of modified soil has been proceed. Many scholars have made study on the engineering properties of modified expansive soil with different materials(Ahmed et al. 2011; Abd, 2013).

The study of modified expansive soils were began in the 1980s, according to the disease in Ping $\mathrm{Ru}$ Road (Bao-Ru section), special study about the effect of modified expansive soil was set up. Lime(Sun \& Li, 2010) and cement (Osula, 1996) are ones of the most common and successful soil stabilizers. Some chemical additives are used with lime, and are found to be useful in accelerating the interaction between lime/cement and soil. However, the cost of modification by these two kinds is higher, and the use of building materials is also increased. To improve the soil properties by using industrial waste, this method not only reduce the material consumption, but also solve the problem caused by industrial waste such as land occupation and polluting the environment. Fly ash (Khoury \& Zaman, 1787), Gypsum Waste Plasterboard (Ahmed et al. 2011) and fibers (Abd, 2013) have been used as modified materials by some researchers.

Cement kiln dust (CKD) is produced from a cement kiln by exhaust gases, and captured by the kiln's air pollution control system. CKD is the biggest waste produced by the process of cement except $\mathrm{CO}_{2}$, and emissions equivalent is $10 \%$ to $20 \%$. In China, according to $10 \%$ of the conservative calculations, the Cement kiln dust emissions is nearly 200 million tons every year, so in most cement plants, disposal of CKDs is a substantial economical and environmental problem. In general, CKDs are mixtures of airborne particles of cement raw materials, partly processed cement components, and volatile components condensed on their surfaces. They vary in composition, but most of them contain silica, calcium carbonate, and $\mathrm{CaO}$ (free lime); many also contain alkali sulfates and chlorides and sometimes other minor components. These make CKDs potentially valuable materials for stabilizing soils(Miller \& Azad, 2000), especially when the CKD contains a lot of free lime (CaO), it will be a good candidates for stabilizing clayey soils containing kaolinite mineral (Peethamparan et al. 2006). 
Many researchers have made study on the CKD treated expansive soil, and results showed that CKD can decrease the expansive properties obviously (Miller \& Azad, 2000), and increase the strength properties meanwhile (Peethamparan et al. 2009). However, the effect of CKD treated expansive soils is connected with the physical and chemical composition of CKD (Bhatty et a. 1996); different CKD in different area cannot be used directly. So, in this paper, the authors focused on investigations of the effectiveness of CKD produced in China as soil stabilizers for expansive soil located in Western China. Different proportions of CKD content were added to expansive soil, and laboratory tests were conducted on mixtures of expansive soil-CKD for shear strength property.

\section{MATERIALS AND PROCEDURE}

\section{Materials}

Expansive soil used in this investigation was obtained from the City of Ankang in Shanxi province in China. It is Brown silty clay, and was selected at a depth of about $1.5-2.0 \mathrm{~m}$. A field density test was carried out, and the disturbed soil was excavated, placed in plastic bags and transported to the Laboratory for preparation and testing. The Natural water content is $6.15 \%$, relative density is 2.76 , plasticity index is 40.41, according to the method recommended in GBJ112-87Standard for construction technical of expansive soil region (in PRC), this soil belongs to weak expansive soil. Particle size distribution curve was shown in Figure 1.

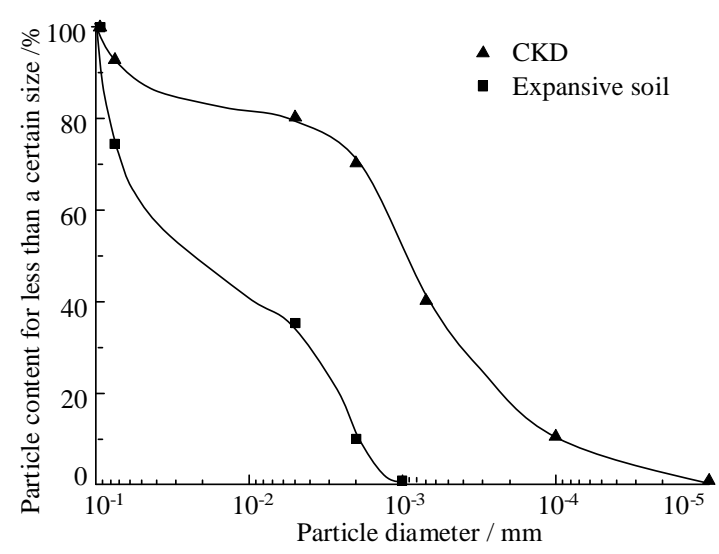

Figure 1 Particle size distributions of expansive soil and CKD

The cement kin dust (CKD) was supplied by a JingYang cement company in Shanxi province in China. It is offwhite thinner powder, the Natural water content is $6.15 \%$ and relative density is 2.76 . Particle size distribution curve was shown in Figure 1.

\section{Experimental procedure}

Laboratory tests are according to the JTJ051-93 Standard for Road soil test (in PRC). CKD content ratio $(\mathrm{Rc})$ is defined as the dry mass of $\mathrm{CKD}$ to the dry mass of the expansive soil-CKD mixtures. To prepare swell test specimens, CKD was added to expansive soil with different content ratio and was initially mixed with a spoon. Then distilled water was added to the mixtures with water content of $22 \%$, and then the soils were mixed carefully by hand until a uniform mixture was obtained. The mixtures were placed in plastic bags and sealed to avoid the loss of water, and allowed to cure in a humidor for $24 \mathrm{~h}$. Compacted tests were conducted by JDS-2 standard compaction apparatus. Strength tests were prepared by statically compacting in a confining ring, the initial dry density for all the specimens were $1.68 \mathrm{~g} / \mathrm{cm} 3$ with $22 \%$ water content according to the maximum dry density and optimum water content for expansive soil. And then specimens were cut by the standard cutting ring $(H=20 \mathrm{~mm}, \Phi 61.8 \mathrm{~mm})$ for later tests.

In addition, in order to study the effect of curing ages on the shear strength, tests were conducted on specimens with curing ages of 1,7,14 and 28 days. 


\section{RESULTS AND DISCUSSIONS}

\section{Effect of CKD on shearstrength}

Direct shear tests were conducted on expansive soil-CKD mixtures, and the shear strength indices were obtained. The shear stress-vertical stress curves were shown in Figure 2.

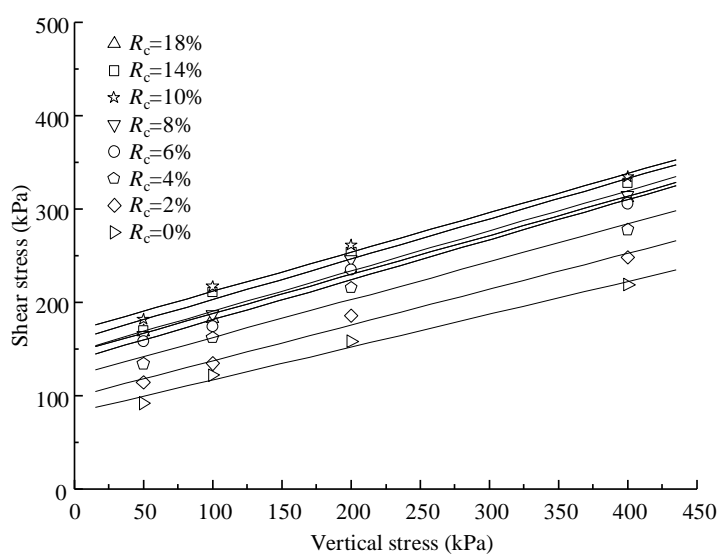

Figure 2 Shear stress-vertical stress

Table 1 Regression equations of shear strength

\begin{tabular}{ccc}
$\begin{array}{c}\text { CKD } \\
\text { con- } \\
\text { tent } \\
1 \%\end{array}$ & Fitting formula & $\begin{array}{c}\text { Correlation } \\
\text { index } r\end{array}$ \\
\hline 0 & $f_{\tau}=71.75+\sigma \operatorname{tg} 19.37^{\circ}$ & 0.9926 \\
2 & $f_{\tau}=98.67+\sigma \operatorname{tg} 21.01^{\circ}$ & 0.9932 \\
4 & $f_{\tau}=121.54+\sigma \operatorname{tg} 22.07^{\circ}$ & 0.9886 \\
6 & $f_{\tau}=137.91+\sigma \operatorname{tg} 22.90^{\circ}$ & 0.9931 \\
8 & $f_{\tau}=147.48+\sigma \operatorname{tg} 23.31^{\circ}$ & 0.9924 \\
10 & $f_{\tau}=169.45+\sigma \operatorname{tg} 23.31^{\circ}$ & 0.9932 \\
14 & $f_{\tau}=159.78+\sigma \operatorname{tg} 23.35^{\circ}$ & 0.9899 \\
18 & $f_{\tau}=145.90+\sigma \operatorname{tg} 22.77^{\circ}$ & 0.9969 \\
\hline
\end{tabular}

Based on the theory of Mohr-Coulomb theory, the relationship between shear strength $\left(f_{\tau}\right)$, vertical stress $(\sigma)$, cohesive force $(c)$ and internal friction angle $(\varphi)$ is satisfy the following formula:

$$
f_{\tau}=c+\sigma \tan \varphi
$$

Least square method was used on Figure 2 to obtain the linear regressions, and the equations were given in Table 1.The change of cohesive force and internal friction angle are shown in Figure 3, it can be seen that with the increase of CKD content, the change of cohesive force is not linear but there is a critical value. For the lower CKD content ratio $\left(R_{\mathrm{c}} \leq 10 \%\right)$, the value for cohesive force from $71.75 \mathrm{kPa}$ for untreated expansive soil to $169.45 \mathrm{kPa}$ for treated soil with $10 \% \mathrm{CKD}$ content. $169.45 \mathrm{kPa}$, the cohesive force was significantly increased by $136 \%$; But when the CKD content ratio is higher $\left(R_{\mathrm{c}}>10 \%\right)$, with the increase of the ratio of CKD adding, the value of cohesive force is reduced. The value of internal friction angle also presented a trend of first increases and then decreases with the increase of CKD content, but the change is not big, which was from $19.37^{\circ}$ for untreated soil to $23.31^{\circ}$ for soil with $10 \%$ CKD content, and then $22.27^{\circ}$ for $18 \%$. 


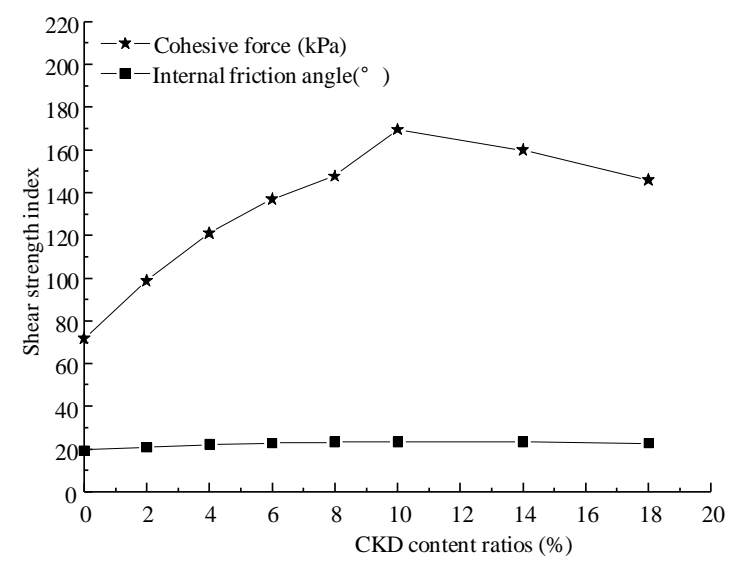

Figure 3 Shear strength index-CKD content ratio

\section{Effect of curing age on shear strength}

In order to obtain the effect of curing age on the shear strength, $10 \% \mathrm{CKD}$ content ratio was chose due to the results of the tests. And the specimens were cured for 1,7,14 and 28 days. Then the shear tests were conducted, results were shown in Figure 4.

It can be seen that with the increase of curing ages, both the cohesive force and internal friction angle were increased. Figure 5 provided the specific change trend, with the increase of curing age, the cohesive force was increased in line with the exponential growth, while the internal friction angle change a little.

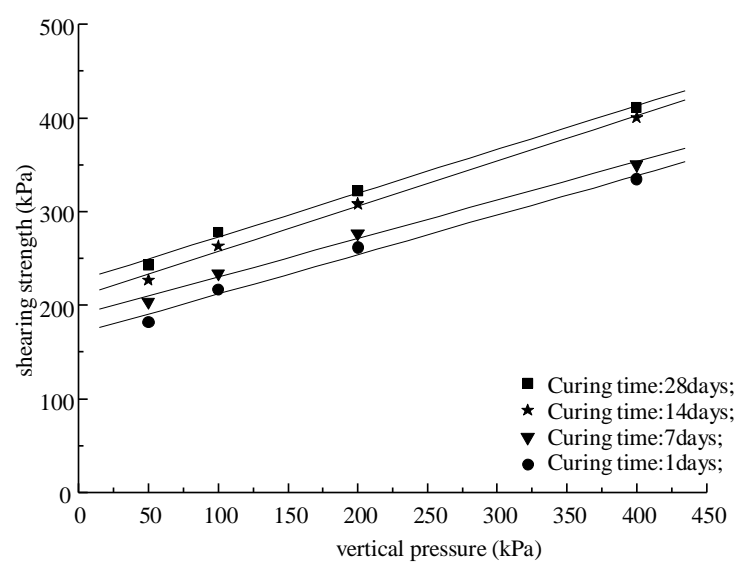

Figure 4 Shear stress-vertical stress

Cement kiln dust (CKD) is the rotary kiln ash, which is a mixture containing a small amount of clinker, treated by high temperature and heated evenly. The carbon in it had been burned into ash glass ball, can be regarded as pozzolanic material. Adding CKD to the expansive soil will make its chemical and physical properties changed. The process of expansive soil was modified by CKD in both physical and chemical reaction, these two aspects work together to promote the fundamental changes in engineering properties. 


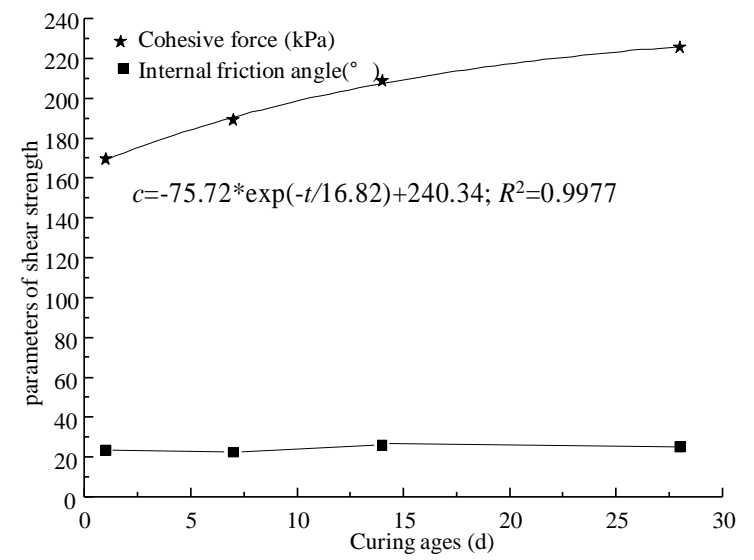

Figure 5 Shear strength index-maintenance period

When CKD is mixed with expansive soil and water, $\mathrm{Ca}(\mathrm{OH})_{2}$ and a small amount of $\mathrm{Mg}(\mathrm{OH})_{2}$ will be produced. $\mathrm{Ca}(\mathrm{OH})_{2}$ and $\mathrm{Mg}(\mathrm{OH})_{2}$ will react with $\mathrm{CO}_{2}$ in the air, and $\mathrm{CaCO}_{3}$ and $\mathrm{MgCO}_{3}$ particles will be created with high strength and water stability.
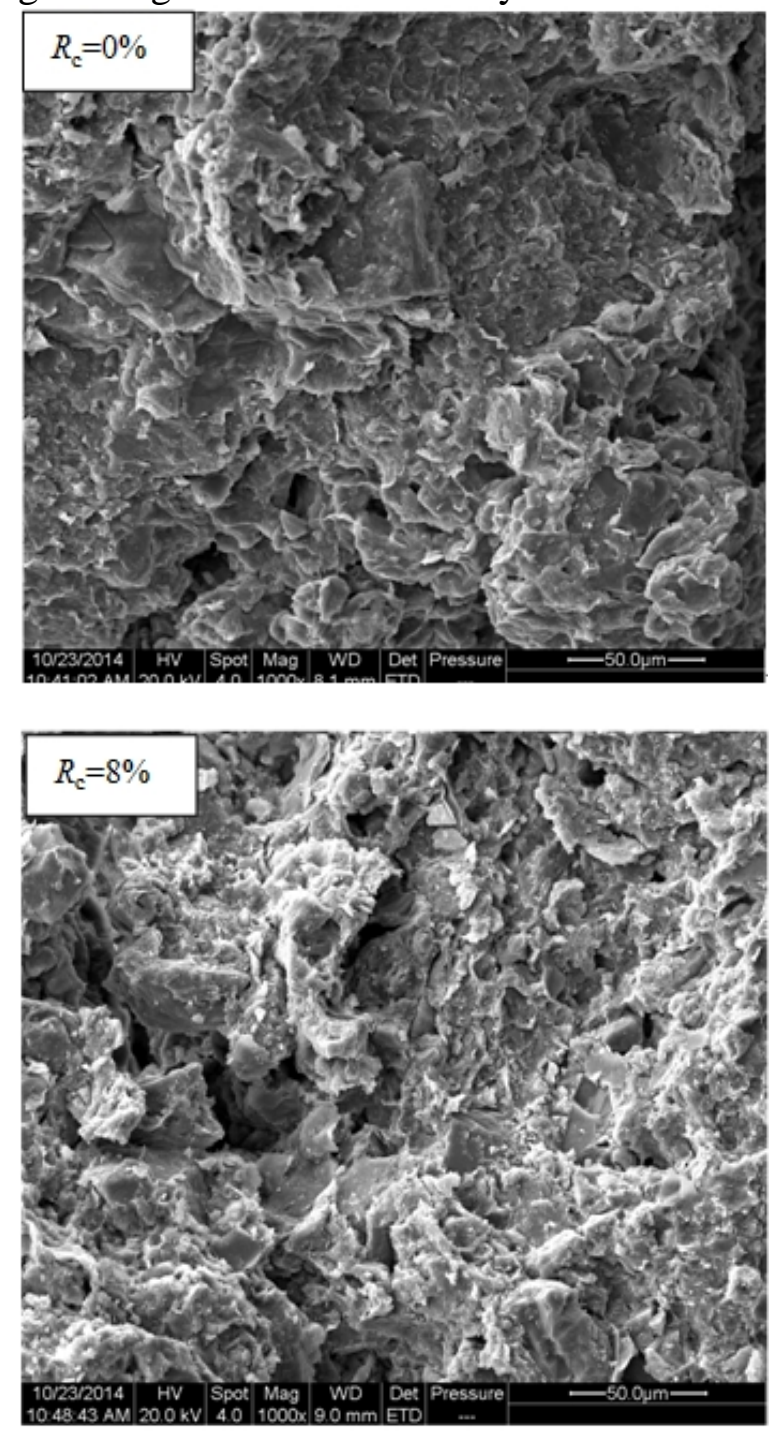


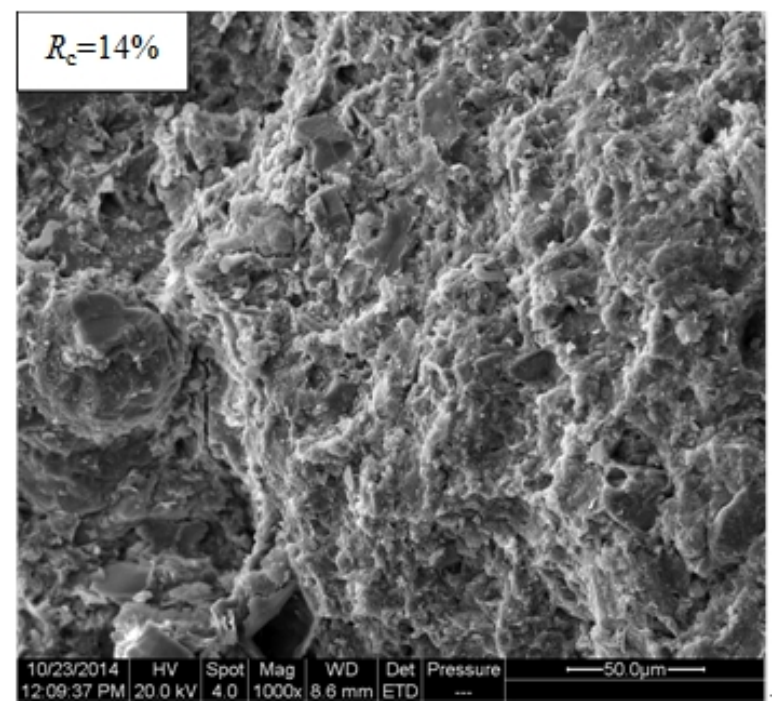

Figure 6 SEM photos of expansive soil-CKD mixtures

Figure 6 shown that with the increase of CKD content ratios, the structure of CKD treated expansive soil was changed from sheet to graininess, then the strength was increased. The reaction equation as follows:

$\mathrm{Ca}(\mathrm{OH})_{2}+\mathrm{CO}_{2}=\mathrm{CaCO}_{3} \downarrow+\mathrm{H}_{2} \mathrm{O}$

\section{CONCLUSIONS}

This paper has made study of expansive soil with different CKD content ratios and curing ages, the following conclusions can be derived:

(1) The shear strength was not change monotonously with the increase of CKD content ratio, there was a critical value which is about $10 \%$. When the CKD content was lower than this value, the cohesive force was increase with its increase, while it decreased after this value. The change of internal friction angle was not obviously.

(2) Curing age also has effect on the shear strength. With the increase of curing ages, the shear strength parameters were increased exponentially, and the value will keeps unchanged after 28 curing age.

(3) Expansive soil modified with CKD can be used as subgrade filling in expansive soil areas, and the optimum mixing CKD content rate is $10 \%$, the suggested curing age is 28 days.

\section{REFERENCES}

Ahmed, A., Ugai, K., and Kamei, T. 2011. Environmental Evaluation for Clayey Soil Stabilized with Gypsum Waste Plasterboard in Japan. Geotechnical Special Publication No. 217, ASCE.

Abd El Megeed Kabasy Mohamed, 2013. Improvement of swelling clay properties using hay fibers. J. Construction and Building Materials 38, 242-247.

Bhatty, J.I., Bhattacharja, S., Todres, H. A. 1996. Use of Cement Kiln Dust in Stabailizing Clay Soils. Portland Cement Association (PCA), Skokie, IL, USA.

Khoury, N. N., and Zaman, M. M. 2002. Effects of wet-dry cycles on resilient modulus of class C fly ash stabilized aggregate base. Transportation Research Record. 1787, Transportation Research Board, National Research Council, Washington, D.C.

Miller, G.A. and Azad, S. 2000. Influence of soil type on stabilization with cement kiln dust, Construction and Building Materials. 14(2): 89-97.

Osula, D.O.A. 1996. A comparative evaluation of cement and lime modification of laterite. J. Engineering Geology, 42(4): 71-78. 
Peethamparan, S., Olek, J., and Helfrich, K. E. 2006. Evaluation of the engineering properties of cement kiln dust (CKD) modified kaolinite clay. Proc., 21st Int. Conf. On solid Waste Technology and Management, Philadelphia, 997-1006.

Peethamparan, S., Olek, J., Diamond, S. 2009, Mechanism of stabilization of Na-montmorillonite clay with cement kiln dust. Cement and Concrete Research. 39: 580-589.

Sun, S.L \& Li, F. 2010, Electrical resistivity measurement for lime-stabilized silt soil. J. Rock and Soil Mechanics, 31(1): 51-55.(In Chinese)

Seed, H.B., Woodward, R.J.Jr. \& Lundgren, R. 1962. Prediction of Swelling Potential for compacted clays, jourma; pf the soil mechanics and foundations division, ASCE, Vol 88, NoSM3. proc,paper 3169, June. 53-87.

Thompson, M.R. 1966. Shear strength and elastic properties of lime-soil mixtures. Highway Research Record. 139, Transportation Research Board, National Research Council, Washington, D.C.

Woeley, H.E. 1959.Methods used in Kansas to Assistant Highway Engineer, State Highway Commission, Kansas, Nov. 